\title{
Blasting Parameter Optimization for Room Adjacent to Cemented Filling Pillar
}

\author{
Q.T. Zeng ${ }^{1,2}$, K.W. Liu ${ }^{1,3, *}$ X.H. Li ${ }^{1}$ and L.G. Wang ${ }^{1}$ \\ ${ }^{1}$ School of Resources and Safety Engineering, Central South University, Changsha 410083, China \\ ${ }^{2}$ Yuxi Mining Co. Ltd., Yunnan Copper Industry (Group), Yuxi 6531000, China \\ ${ }^{3}$ School of Civil and Resource Engineering, the University of Western Australia, Perth 6009, WA, Australia
}

Received 7 June 2016; Accepted 24 September 2016

\begin{abstract}
As a mining method that can achieve highly efficient continuous stoping, the two-step stoping method exploits ore body from pillars to rooms after cemented filling of pillars, thereby making alternate continuous stoping between pillars and rooms after tailing backfilling of rooms. The key of this method is to ensure the stability of cemented filling pillar. The instantaneous effect of dynamic load, which is produced by blasting an adjacent room, is the strongest destructive power to cemented filling pillar. In this study, three room blasting schemes based on the original blasting parameters were proposed to reduce vibration damages to adjacent cemented filling pillar. The propagation of stress waves in rock mass and cemented filling pillar during millisecond-delay blasting was simulated by the ANSYS/LS-DYNA program. Finally, the blasting parameters, including charging pattern, hole spacing, and burden, were optimized based on the simulation results. The optimized blasting scheme was applied for practical room blasting. Results showed that, after the optimized blasting scheme was used, the peak particle velocity (PPV) at cemented filling pillar decreased by $52 \%$ and the cemented filling pillar remained stable with slight damage. Meanwhile, rock fragments after room blasting were even in size and the substantial rock production was only $6 \%$, thereby achieving the ideal blasting effect. Optimized blasting parameters could provide references for room blasting design and operation under two-step stoping.
\end{abstract}

Keywords: Cut-and-fill mining, Optimization on parameters, Room blasting, Cemented backfill pillar, peak particle velocity(PPV)

\section{Introduction}

The cut-and-fill stoping method is extensively applied in the underground mining of metal mines because of its high stoping rate and low dilution ratio [1], [2] , [3], [4]. And the stability of filling pillar in the stoping process is directly related to the operation safety of the stope. Failure of pillar could cause ore dilution and even large-scale stope collapse, which is significant potential safety risks for the staff and equipment during excavation, thus worsening mining conditions and disturbing the normal production of mine enterprise. Therefore, the stability of filling pillar has gradually attracted more attention from foreign and China's mining and related researchers [5], [6], [7]. Besides static load factors, such as ground stress and gravity, the instantaneous effect of dynamic load produced by adjacent room blasting is the most important influencing factor of the stability of filling pillars. The dynamic load has large destructive power to filling pillars, and the corresponding stress wave with high peak particle velocity (PPV) could significantly disturb and damage filling pillars. Filling pillars easily suffer from dynamic collapse, thereby failing to support the stope roof [8], [9], [10] and causing large-scale roof fall offs and rock movement. Therefore, analyzing the dynamic responses and damages of filling pillars under blasting vibration has important practical significance for

*E-mail address: kewei_liu@126.com

ISSN: 1791-2377 @ 2016 Eastern Macedonia and Thrace Institute of Technology. All rights reserved. optimizing blasting parameters and schemes, thereby controlling PPV of blasting stress wave within a reasonable range and maintaining the stability of filling pillars.

\section{State of the art}

At present, the field blasting experiment is still the most effective method to assess the stability of filling pillars under adjacent room blasting. Through field blasting, the dynamic response characteristics of filling pillars under blasting load can be obtained, thus enabling effective adjustment of blasting parameters. Gool [11] conducted a series of studies regarding the effect of the blasting load on the filling pillars. He observed the matching relationship between the PPV and the distance from the charge center and believed that delay time could influence the stability of backfilling to some extent. Emad et al. [12] deemed that blasting of the adjacent room is one of the main causes of filling pillar failure. They further explored the dynamic responses of filling pillars to different blasting parameters. These experimental studies collected analysis data by presetting blasting vibration meters in the field, which is disadvantageous because of its high cost, time-consuming preparation, and strict restrictions on site conditions [13].

With continuous technological development, the numerical simulation method with low cost and high efficiency has been applied in many fields. Many scholars have conducted considerable numerical research on the problems of filling pillars under blasting load by using 
advanced computer software and hardware resources, which overcame the restrictions of the field experiment to a great extent. For example, Lu and Fall [14] constructed a chemistry-viscoplasticity coupling model for evaluating the stability of cemented backfilling under blasting load. $\mathrm{Hu}$ et al. [15] predicted the blast vibration effect in a filling mining environment by ANSYS/LS-DYNA and provided suggestions on blasting approaches with regard to the environment. However, the stability of filling pillars was not investigated. Liu et al. [16] analyzed the effect of charging pattern on filling pillar stability through simulation; however, the analysis only focused on the single factor of charging pattern. From literature reviews, numerical simulation technology has achieved significant progress in research on the blasting stability of filling pillars. Nevertheless, most of the existing studies focused on single blasting parameters and only a few involved multiple blasting parameters. In addition, the studies were mainly theoretical analyses that converted three-dimensional problems into two-dimensional problems for simulation and were limited to single-hole blasting simulations instead of multi-hole and multistage millisecond-delay blasting simulations. Therefore, the practical damages of adjacent filling pillars under room blasting were not comprehensively and accurately reflected. In this study, the propagation of stress wave in rock mass and cemented filling pillar during multi-hole and multistage millisecond-delay blasting was simulated with the ANSYS/LS-DYNA program and the effect of room blasting vibration on adjacent cemented filling pillar under different blasting parameters was analyzed. Finally, rational blasting parameters, including charging pattern, hole spacing, and burden, were optimized to minimize damages of adjacent filling pillar caused by room blasting. The optimized room blasting scheme was used in practical ore production. The results could provide references for room blasting design and operation under two-step stoping.

The remainder of this paper is organized as follows: Section 3 describes the research background of two-step stoping in Dahongshan Copper Mine and introduces the material models and algorithm used in the dynamic model and the designs of different blasting schemes. Then, the appropriate boundary conditions are applied to the model and the rationality of blasting delay is verified. Section 4 analyzes the calculated effective plastic strain, evaluates the damages and stability of the cemented filling pillar, and practices the optimized blasting scheme. Section 5 summarizes the conclusions.

\section{Methodology}

\subsection{Background}

Dahongshan Cooper Mine is a medium-thickness $\mathrm{Cu}-\mathrm{Fe}$ paragenetic deposit with a gentle dip, covering three layers of the copper ore body and four layers of the iron ore body. Copper and iron beds are alternately distributed. The twostep stoping method, which exploits ore bodies from pillars to rooms after cemented filling of pillars, thereby creating alternate continuous stoping between pillars and rooms after tailing backfilling of rooms, was adopted to make full use of copper and iron resources and achieve the economies of scale. The room and pillar layouts are shown in Fig. 1. Surface filling station, pillar filling, and cemented filling pillars are shown in Figs. 2, 3, and 4, respectively. A strong superimposed effect, which caused severe vibration and seriously destroyed the adjacent filling pillar, was formed during room blasting because of the excessive charge of the single blasting hole adjacent to the filling pillar, the small spacing, and the big burden. The original blasting parameters have to be optimized to control the vibration caused by room blasting within the tolerance of filling pillars.

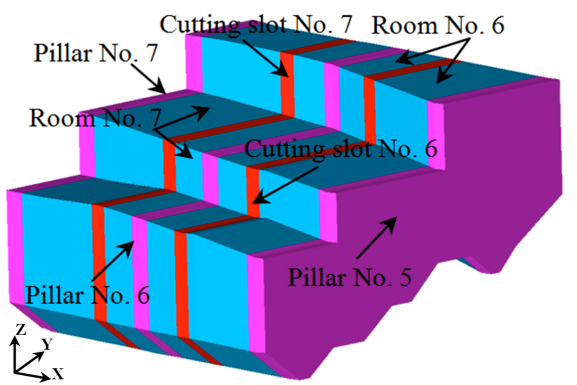

Fig.1. Room and pillar layouts in two-step stope of the Dahongshan Copper Mine
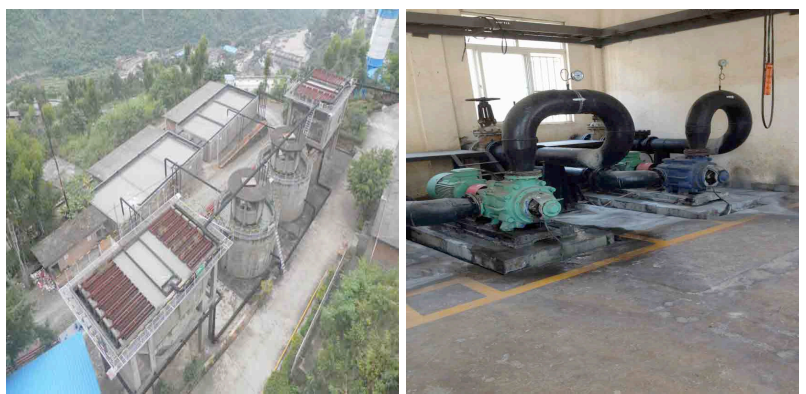

Fig.2. Surface filling station
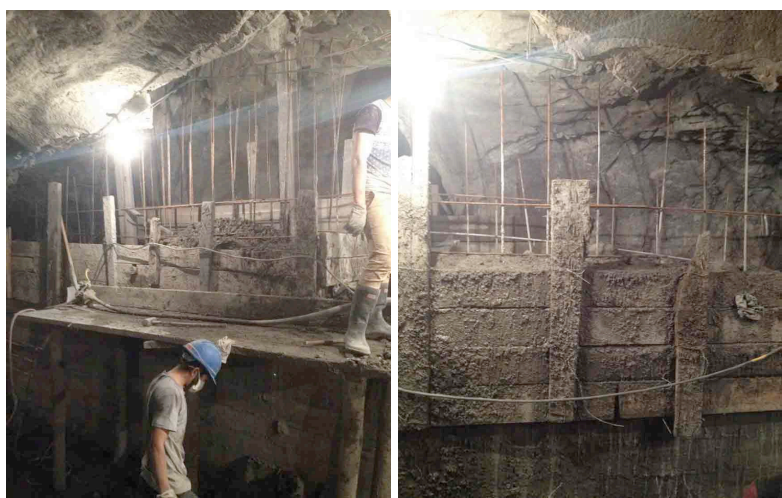

Fig.3. Pillar filling
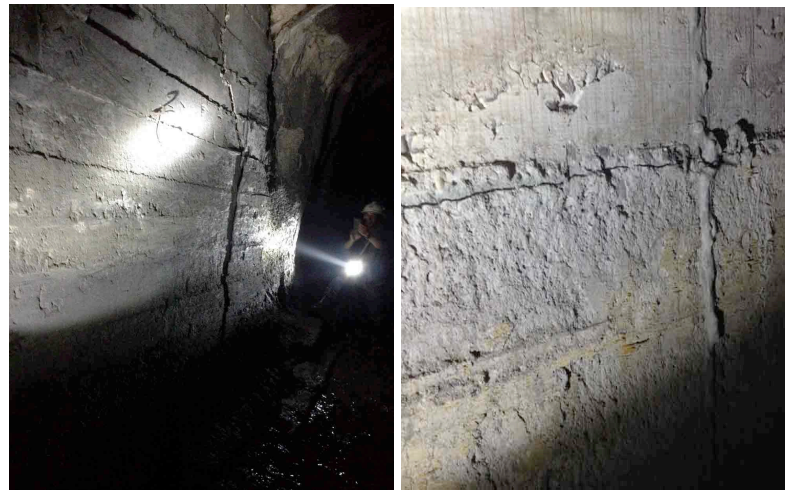

Fig.4. Cemented filling pillar

\subsection{Material Models and Algorithm}

The ANSYS/LS-DYNA program was used in this simulation. The ANSYS/LS-DYNA can not only provide 
multiple material models and equations of state but can also accurately and reliably process highly nonlinear problems, such as blasting analysis [17]. This program is applicable to the numerical simulation of rock blasting.

(1) Equation of the state of the high explosive

Pressure $(P)$ acting on the element after blasting could be described by the JWL equation of state by using LS-DYNA embedded explosive [18]:

$$
P=A\left(1-\frac{\omega}{R_{1} V}\right) e^{-R_{1} V}+B\left(1-\frac{\omega}{R_{2} V}\right) e^{-R_{2} V}+\frac{\omega E}{V}
$$

where $P$ is the detonation pressure, $V$ is the relative volume, $E$ is the internal energy in unit volume with an initial value of $E_{0}$, and $A, B, R_{1}, R_{2}$, and $\omega$ are the material constants.

The parameters of the ammonium nitrate (AN) explosive used in room blasting are listed in Table 1.

Table 1. Parameters of the AN explosive

\begin{tabular}{c|c|c|c|c|c|c|c}
\hline $\begin{array}{c}\text { Density } \\
\left(\mathbf{g} \cdot \mathbf{c m}^{-\mathbf{3}}\right)\end{array}$ & $\begin{array}{c}\text { Detonation } \\
\text { velocity } \\
\left(\mathbf{m} \cdot \mathbf{s}^{-1}\right)\end{array}$ & $\begin{array}{c}\boldsymbol{A} \\
(\mathbf{G P a})\end{array}$ & $\begin{array}{c}\boldsymbol{B} \\
(\mathbf{G P a})\end{array}$ & $\boldsymbol{R}_{\mathbf{1}}$ & $\boldsymbol{R}_{\mathbf{1}}$ & $\boldsymbol{\omega}$ & $\begin{array}{c}\boldsymbol{E}_{\mathbf{0}} \\
(\mathbf{G P a})\end{array}$ \\
\hline 1.20 & 4,300 & 42.00 & 0.44 & 3.55 & 0.16 & 0.41 & 3.15 \\
\hline
\end{tabular}

(2) Material models of rock and filling

The material model of MAT_BLASTIC_KINEMATIC

[19] is selected to simulate the rock mass behavior. This material model is closely related to strain. The strain rate could be calculated from the Cowper-Symonds model, and the yield stress could be expressed as:

$\sigma_{y}=\left[1+\left(\frac{\dot{\varepsilon}}{C}\right)^{\frac{1}{p}}\right]\left(\sigma_{0}+\beta E_{p} \varepsilon_{p}^{e f f}\right)$

where $\sigma_{0}$ is the initial yield stress, $\dot{\varepsilon}$ is the strain rate, $\varepsilon_{p}^{e f f}$ is the effective plastic strain, and $E_{p}$ is the plastic hardening modulus, which was calculated from:

$$
E_{p}=\frac{E_{\mathrm{tan}} E}{E-E_{\mathrm{tan}}}
$$

$C$ and $p$ are the parameters of strain rate.

The dynamic characteristics of cemented filling pillar under the instantaneous effect of the dynamic load are unknown because an accurate mathematical description of the failure characteristics of cemented filling pillar under blasting load is unavailable. Therefore, the constitutive features of cemented filling pillar were simplified into linear elastomer when selecting material model to ensure the reliability of the simulation process and conclusions with regard to the integrity of the simulation prototype. The compressive strength of cemented filling pillar was determined as the actual compressive strength at the 28th day (7.13 MPa). Moreover, sands in the charging pattern were mainly used to separate explosives and slightly influenced the interaction between explosive and ore rocks in the computation process. Therefore, the material model and the parameters of sands were consistent with those of ore rocks. The physical and mechanical parameters of ore rocks are shown in Table 2.
Table 2. Physical and mechanical parameters of ore rocks

\begin{tabular}{c|c|c|c|c}
\hline $\begin{array}{c}\text { Density } \\
\left(\mathbf{g} \cdot \mathbf{c m}^{-\mathbf{3}}\right)\end{array}$ & $\begin{array}{c}\text { Elasticity } \\
\text { modulus (GPa) }\end{array}$ & $\begin{array}{c}\text { Poisson's } \\
\text { ratio }\end{array}$ & $\begin{array}{c}\text { Yield } \\
\text { strength } \\
(\mathbf{M P a})\end{array}$ & $\begin{array}{c}\text { Tangent } \\
\text { modulus } \\
(\mathbf{M P a})\end{array}$ \\
\hline 2.88 & 66.80 & 0.26 & 4.90 & $\mathbf{5 . 1}$ \\
\hline
\end{tabular}

In summary, the model defined the materials of explosives, rocks, filling, and sands, including milliseconddelay and multiple blasting holes. Considering the complexity of the blasting model and the RAM limit of the computer, the model was calculated by the conode algorithm [20]. The conode algorithm uses the same nodes, which means that the explosive elements and the contacted medium elements share the same nodes. This algorithm can protect computation continuity and has strong robustness, although the model gridding could be significantly distorted sometimes. Computation accuracy could be guaranteed by properly adjusting the failure options. For complicated models, the conode algorithm is relatively simple and can make full use of the computer. The calculated results agree well with the practical blasting engineering.

\subsection{Four Blasting Schemes}

Blasting parameters are often determined by empirical relations in practical engineering. In this blast design, blasting holes are set parallel and the burden could be obtained from [21]:

$$
W=d \sqrt{\frac{7.85 \rho \lambda}{q m}}
$$

where $d$ is the diameter of blast holes, $\rho$ is the charge density, $\lambda$ is the charge coefficient $(0.7-0.85), q$ is the explosive consumption per unit volume of rocks, and $m$ is the deep hole spacing ratio or deep hole adjacent coefficient $(0.8-1.1$ for parallel blasting holes).

The room blasting scheme at the east of cutting slot no. 7 and adjacent to the filling pillar no. 6 of the Dahongshan Copper Mine was optimized. Appropriately increasing the hole spacing, reducing the burden, and damping more stress wave in the air beyond the rock boundary can not only result in good fragmentation but can also weaken blast-induced vibration $[22,23]$. Therefore, appropriate burden and hole spacing should be determined together with practical mining engineering based on the original room blasting scheme. In addition, the charging pattern should be redesigned because of the excessive charge of the single blasting hole in the original scheme.

The blasting schemes were designed based on the actual size of the stope, in which the diameter of the blasting holes was $165 \mathrm{~mm}$. The blasting hole layouts and charging patterns of four blasting schemes are shown in Figs. 5 and 6. Scheme 1 was the original charging pattern (alternate arrangement of $4 \mathrm{~m}$ explosives and $0.5 \mathrm{~m}$ sands) with $4.5 \mathrm{~m}$ hole spacing, $1.2 \mathrm{~m}$ burden between two rows of holes, 3.3 $\mathrm{m}$ burden from the outer row of the holes to the rock boundary, and 11 blasting holes. Scheme 2 used a new charging pattern (alternate arrangement of $0.5 \mathrm{~m}$ explosives and $0.5 \mathrm{~m}$ sands) with $4 \mathrm{~m}$ hole spacing, $1.5 \mathrm{~m}$ burden between the two rows of the holes, $2.5 \mathrm{~m}$ burden from the outer row of the holes to the rock boundary, and 13 blasting holes. Scheme 3 used the same charging pattern as Scheme 2 with $4.5 \mathrm{~m}$ hole spacing, $1.5 \mathrm{~m}$ burden between the two rows of holes, $2.5 \mathrm{~m}$ burden from the outer row of the holes to the rock boundary, and 11 blasting holes. Scheme 4 used another charging pattern (alternate arrangement of $0.5 \mathrm{~m}$ 
explosives and $1 \mathrm{~m}$ sand) with $4.5 \mathrm{~m}$ hole spacing, $1.5 \mathrm{~m}$ burden between the two rows of holes, $2.5 \mathrm{~m}$ burden from the outer row of the holes to the rock boundary, and 11 blasting holes. In all four blasting schemes, the first row of holes was detonated first and the second row was detonated 50 milliseconds later.
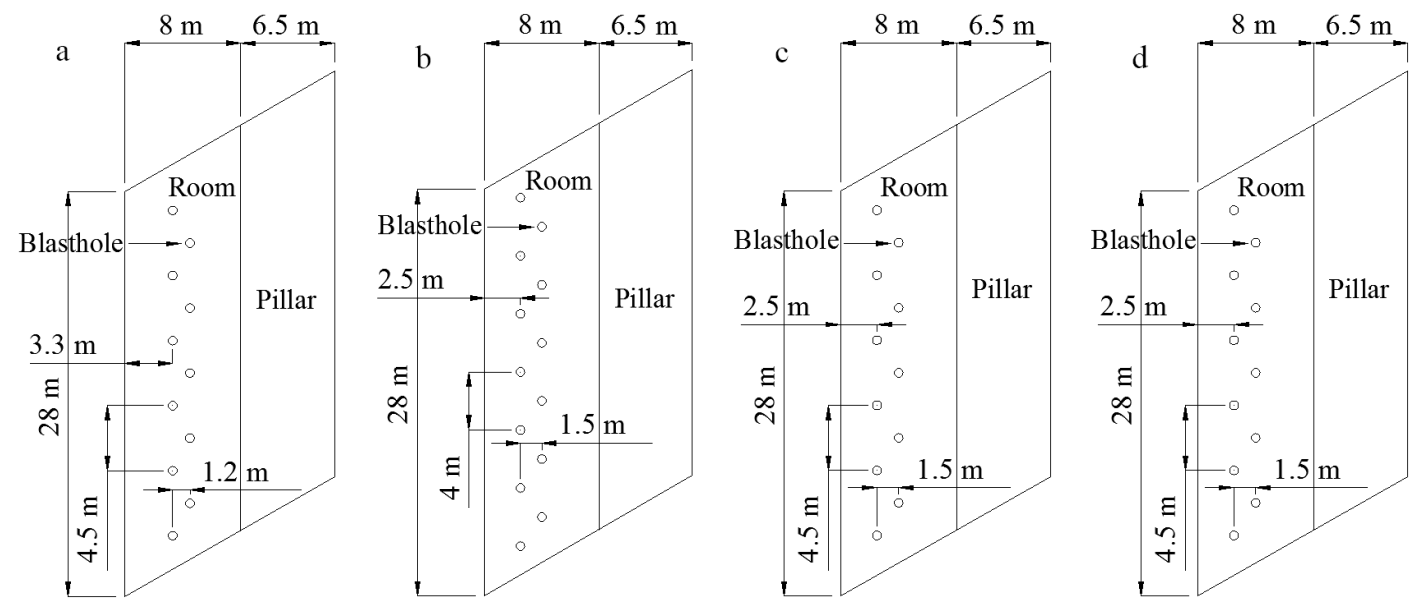

Fig.5. Blasting hole layouts: (a) Scheme 1, (b) Scheme 2, (c) Scheme 3, and (d) Scheme 4
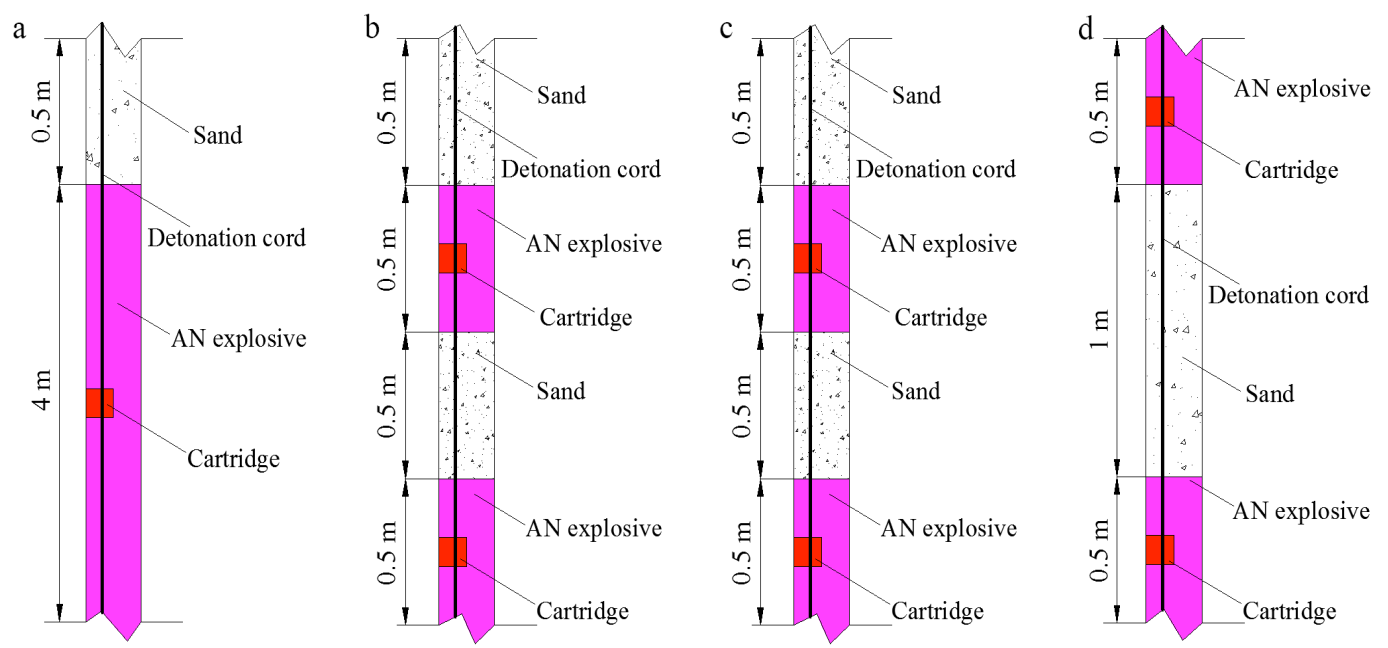

Fig.6. Charging patterns: (a) Scheme 1, (b) Scheme 2, (c) Scheme 3, and (d) Scheme 4

\subsection{Boundary Conditions}

When considering the computing capacity of the computer, characterizing the continuous rock mass by a finite size model is necessary. In the simulation, nonreflecting boundary conditions were applied on the external surface of the finite domain to avoid reflected waves at the boundaries, which may cause superimposed disturbances to the stress waves normally propagating in the model. The mechanism of nonreflecting boundary condition is to consume stress wave energies at model boundaries by damping settings to completely avoid wave reflection at the boundaries. Therefore, nonreflecting boundary conditions were set on the south, north, and east numerical surfaces of the model, whereas the remaining surfaces were set as free boundaries. The height of the model was set to $6 \mathrm{~m}$ to replace the entire deep holes and shorten the run time of the computer. In every scheme, six blasting holes (three for each row) were selected for simulation.

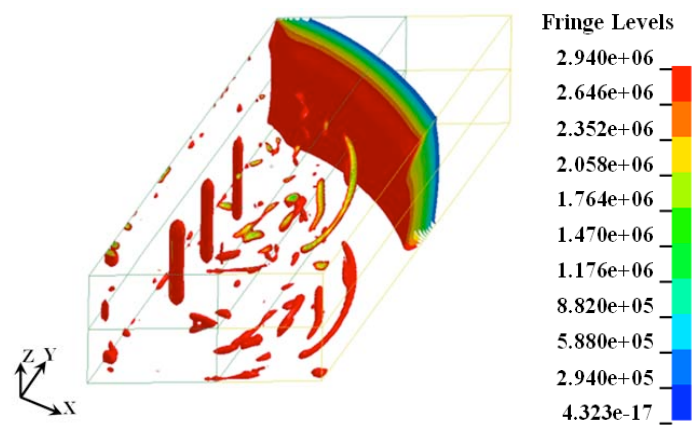

Fig.7. Iso-surfaces of effective stress after detonation of the first row of blasting holes in Scheme 1

Fig. 7 shows the iso-surfaces of the effective stress after the first row of blasting holes in Scheme 1 were detonated. At three nonreflecting boundaries, good transmission effects were obtained. From the spatial form of the iso-surfaces, the stress waves formed after detonating the long cylindrical explosives in Scheme 1, which diffused as approximate 
cylindrical waves, thereby indicating that using a model height of $6 \mathrm{~m}$ instead of the entire deep holes in the simulation analysis is feasible.

\subsection{Delay Time Test}

A node on the west surface of the filling pillar was randomly selected to test superimposed vibration of millisecond-delay detonation (Fig. 8). The time-history curve of velocity at the node was extracted. After the millisecond-delay detonation of the first and second rows, no obvious superimposed vibration between two stages occurred, thereby indicating that the delay time of 50 milliseconds was rational.
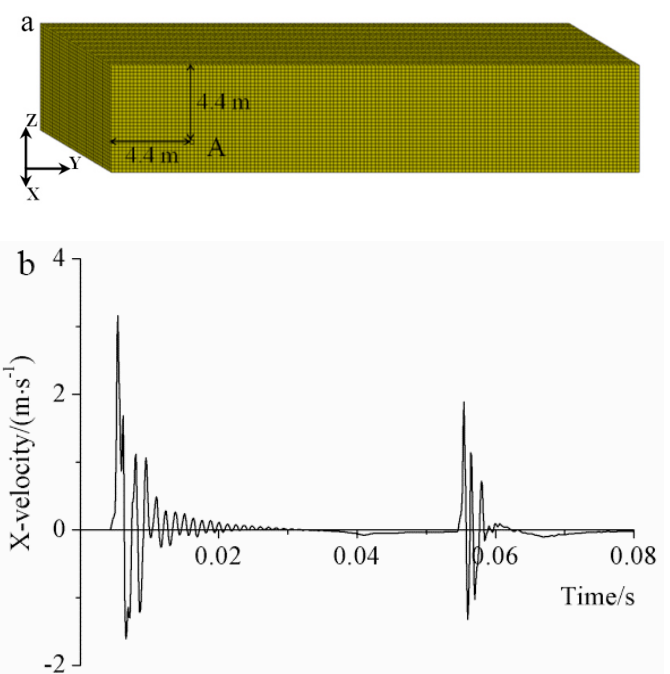

Fig.8. Node location and time-history curve of velocity: (a) node location and (b) time-history curve of velocity

\section{Result analysis and discussion}

\subsection{Effective Plastic Strain}

The iso-surfaces of the effective plastic strain of the four blasting schemes at $0.092 \mathrm{~s}$ are shown in Fig. 9. In all four blasting schemes, effective plastic strain diffused all around, mainly along the horizontal direction. Effective plastic strain gradually decreased as it moved away from the blasting holes. Effective plastic strain overlap occurred after the detonation of two rows of blasting holes. Compared with the remaining three blasting schemes, Scheme 1 had the greatest effective plastic strain area and the strongest high-strain overlap, which are mainly attributed to the smaller row spacing and the higher charge, thereby indicating that Scheme 1 has the largest reach of blasting and the best crushing of ore body. However, a substantial burden from the outer row of the holes to the rock boundary was adopted and thereby failed to control the stress damped mainly in air (cutting slot), which significantly enhanced vibration level and was against the stability of adjacent filling pillars.

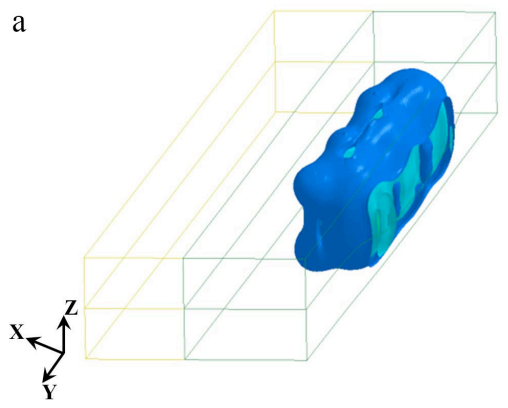

$$
\begin{gathered}
\text { Fringe Levels } \\
1.250 \mathrm{e}+00 \\
1.125 \mathrm{e}+00] \\
1.000 \mathrm{e}+00 \\
8.752 \mathrm{e}-01 \\
7.502 \mathrm{e}-01 \\
6.253 \mathrm{e}-01] \\
5.003 \mathrm{e}-01 \\
3.754 \mathrm{e}-01 \\
2.504 \mathrm{e}-01 \\
1.255 \mathrm{e}-01 \\
5.445 \mathrm{e}-04
\end{gathered}
$$
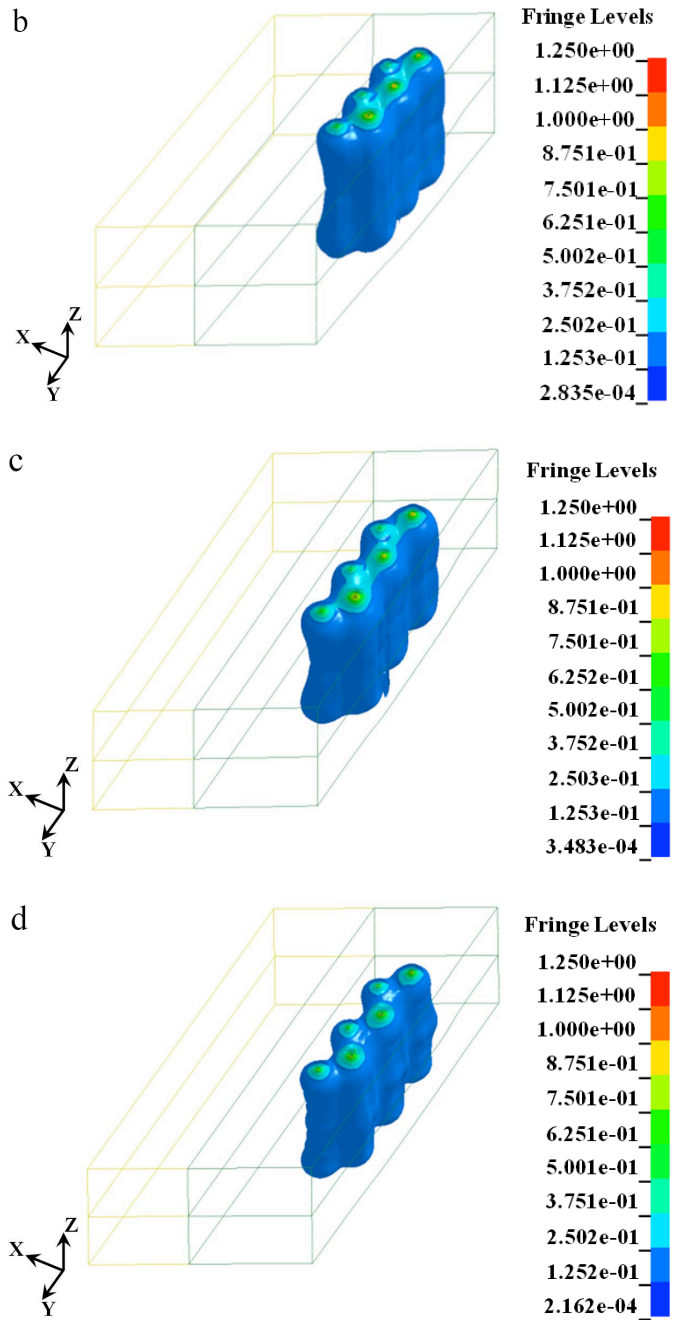

Fig.9. Iso-surface of effective plastic strain at 0.092 s: (a) Scheme 1, (b) Scheme 2, (c) Scheme 3, and (d) Scheme 4

\subsection{Analysis of Damages and Stability of Filling Pillar} In practical applications, structural damages are often evaluated by some empirical criteria, which are mainly based on the PPV of the stress wave caused by blasting [24]. Furthermore, previous research [15] has reported that failures of vertical profiles (e.g., rock roadway and filling) are mainly caused by particle vibration perpendicular to these profiles. Therefore, a comparative analysis of the damages and stability of cemented filling pillar was implemented using the time-history curves of X-velocity of nodes. Six representative nodes (Fig. 10a) were selected from the west surface of the filling pillar adjacent to the blasted room, and their time-history curves of X-velocity and PPVs in the calculated results of four blasting schemes were extracted (Figs. $10 \mathrm{~b}$ to $10 \mathrm{e}$ ).

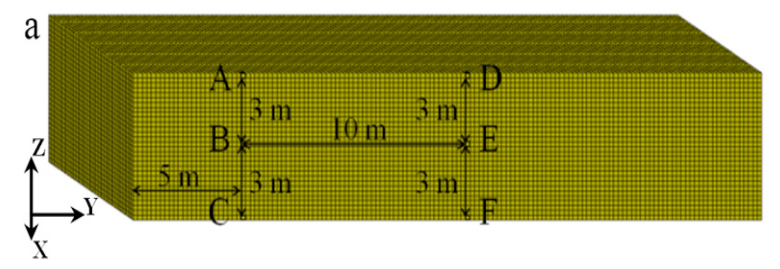



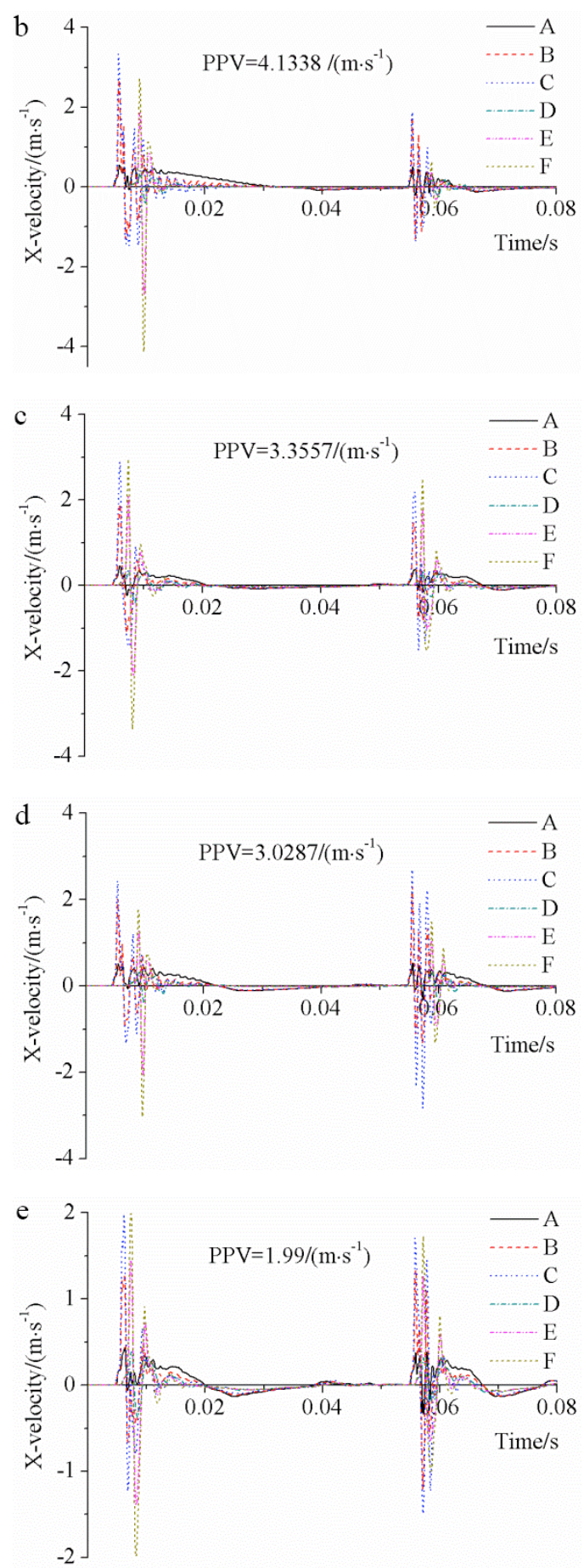

Fig.10. Node locations and time-history curves of X-velocity: (a) node locations, (b) Scheme 1, (c) Scheme 2, (d) Scheme 3, and (e) Scheme 4

Fig. 10 shows that the PPVs of the four blasting schemes were $4.1338,3.3557,3.0287$, and $1.99 \mathrm{~m} \cdot \mathrm{s}-1$, respectively. In practical engineering, an intrinsic fissure exists between filling and ore body, which has similar vibration attenuation effect with pre-cracking and fault. Furthermore, with regard to environmental squeeze and constraints, fillings could tolerate stronger vibration in practical engineering [16]. In addition, few PPV-based empirical criteria or specifications can be found for damage evaluation of cemented filling pillar. In this study, damages of cemented filling pillar were evaluated by the engineering analogy method using the empirical criteria of Dowding [25], which was used in the jointed rock mass. In the empirical criteria of Dowding, the damage of unlined tunnel was divided into four levels, namely, joint movement and falling loose stones, intermittent failure, local failure, and complete closure. When the PPV exceeded $2 \mathrm{~m} \cdot \mathrm{s}-1$, rock failure in the tunnel began. From the preceding empirical criteria, cemented filling pillar in Scheme 1 was seriously damaged after room blasting. Although the blasting parameters in Schemes 2 and 3 were optimized, the PPVs were still higher than $2 \mathrm{~m} \cdot \mathrm{s}-1$ and the cemented filling pillar were also significantly damaged. In Scheme 4, the PPV was lower than $2 \mathrm{~m} \cdot \mathrm{s}-1$ and the vibration intensity was $52 \%$ lower than that in Scheme 1, which would keep the cemented filling pillar stable.

\subsection{Field Application}

Scheme 4 was adopted in the room (adjacent to the filling pillar no. 6) blasting at the east of the cutting slot no. 7 in Dahongshan Copper Mine. Rock fragment size after detonation is shown in Fig. 11a. Except for a few large rocks, rock fragment size was relatively even and substantial rock production was only $6 \%$. Meanwhile, the room blasting only resulted in slight damage to the local surface of the cemented filling pillar no. 6 (Fig. 11b), thereby ensuring the overall integrity and stability of the pillar.

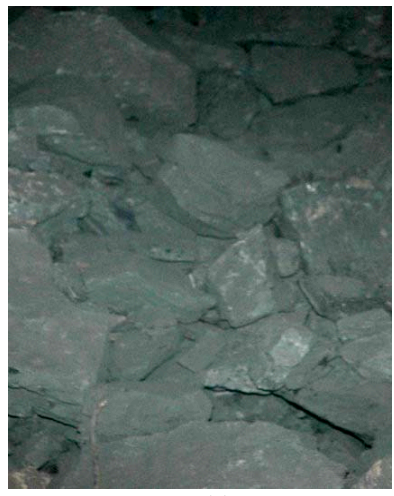

(a)

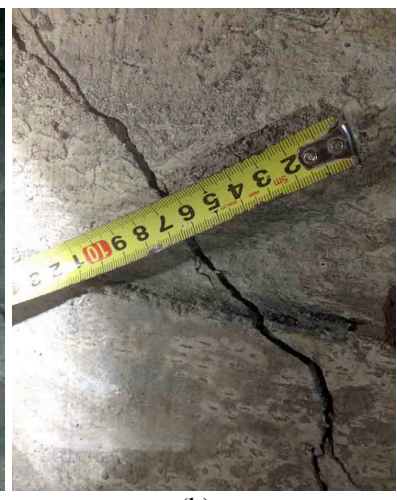

(b)
Fig.11. (a) Ore rock fragmentation size and (b) local surface damages

\section{Conclusions}

Multi-hole and multistage millisecond-delay blasting was used to simulate the propagation of stress wave in rock mass and cemented filling pillar during the blasting process to reduce vibration-induced damages of cemented filling pillar adjacent to room blasting and maintain the stability of the filling pillar. Charging pattern, hole spacing, and burden were optimized. The optimized blasting scheme was applied in practical engineering. The conclusions obtained are as follows:

(1) In Scheme 1, the stress waves formed after the detonation of the long cylindrical explosives diffused as approximate cylindrical waves, which verified not only the stress wave propagation theory of cylindrical charging pattern but also indicated that using the finite height model instead of the entire deep holes in the numerical simulation was feasible.

(2) The rationality of delay time was analyzed by using the time-history curve of velocity at the extracted node, thereby providing scientific references for the determination of delay time in actual blasting operation, eliminating superimposed vibration, and effectively reducing stope vibration.

(3) Comparing PPVs at the cemented filling pillar of the four blasting schemes, Scheme 4 exhibited the best PPV, 
followed by Schemes 3, 2, and 1, successively. The vibration of Scheme 4 was $52 \%$ lower than that of Scheme 1 , thereby indicating that appropriately increasing the hole spacing and subsequently reducing the burden to control the damped stress in the air could weaken blasting vibration to some extent. Thus, the blasting vibration intensity could be significantly decreased by adjusting the explosive charge, which is beneficial for keeping the stability of the adjacent pillar.

(4) The optimized Scheme 4 was applied in room blasting of the two-step stoping in Dahongshan Copper Mine. The rock fragment size after detonation was uniform, together with a few large rocks. The cemented filling pillar remained integral and stable, except for the slight damage on the local surfaces.

Optimizing the blasting parameters for rooms adjacent to the cemented filling pillars can significantly reduce blasting vibration. Further studies based on the established model, particularly on the dynamic response law of filling pillars and the effect of filling strength on the dynamic stability of pillars at different distances to the explosive center, are necessary.

\section{Acknowledgements}

This work was supported by the National Natural Science Foundation of China under the project No.51304239.

\section{References}

1. William A., and Richard L., "Underground mining methods", Society for mining, metallurgy, and exploration, Inc. Colorado, USA, 2001, pp. 287-357.

2. Xie S. J., "Underground Mining of Metal Mines", Beijing: Metallurgical Industry Press, China, 2013, pp. 246-261.

3. Wu D., Cai S. J., Yang W., Wang W. X., and Wang Z., "Simulation and experiment of backfilling pipeline transportation of solid-liquid two-phase flow based on CFD", The Chinese Journal of Nonferrous Metals, 22(7), 2012, pp. 2133-2142.

4. Wang X. M., Zhao J. W., and Zhang D. M., "Optimal prediction model of flocculating sedimentation velocity of unclassified tailings", The Chinese Journal of Nonferrous Metals, 25(3), 2015, pp. 793-798.

5. Fall M., Celestin J. C., Pokharel M., and Toure M., "A contribution to understanding the effects of curing temperature on the mechanical properties of mine cemented tailings backfill", Engineering Geology, 114(3), 2010, pp. 397-413.

6. Deng D. Q., Gao Y. T., Wu S. C., and Yu W. J., "Experimental study of destructive energy dissipation properties of backfill under complicated stress condition", Rock and Soil Mechanics, 31(3), 2010, pp. 737-742.

7. Xiu G. L., Dang W. G., and Liu Z. X., "Microstructure test and macro size effect on the stability of cemented tailings backfill", International Journal of Digital Content Technology and Its Applications, 6(14), 2012, pp. 387-397.

8. Doerner C., and Andres C., "Effect of delayed backfill on open stope mining methods", Doctoral dissertation of The University of British Columbia, Vancouver, Canada, 2005, pp. 1-16.

9. Qiu X. Y., Shi X. Z., and Huang D., "Safety control technology of large-diameter long-hole blasting", Nonferrous Metals Engineering, 5(1), 2015, pp. 137-140.

10. Zaka E. M., Mitri H., and Kelly C., "Effect of blast-induced vibrations on fill failure in vertical block mining with delayed backfill”, Canadian Geotechnical Journal, 51(9), 2013, pp. 975983.

11. Gool B. V., "Effects of blasting on the stability of paste fill stopes at Cannington Mine", Doctoral dissertation of James Cook University, Queensland, Australia, 2007, pp. 4-23.

12. Emad M. Z., Mitri H. S., and Henning J. G., "Effect of blast vibrations on the stability of cemented rockfill", International Journal of Mining, 26(3), 2012, pp. 1-11.
13. Liu Y. P., Gong M., and Huang G. H., "Numerical analysis method for optimization charging structure of deep-hole blasting and its application", Rock and Soil Mechanics, 33(6), 2012, pp. 1883-1888.

14. Lu G., and Fall M., "A coupled chemo-viscoplastic cap model for simulating the behavior of hydrating cemented tailings backfill under blast loading", International Journal for Numerical \& Analytical Methods in Geomechanics, 40(8), 2016, pp. 1123-1149.

15. Hu J. H., Lei T., Zhou K. P., and Chen Q. F., "Forecast and control of blasting vibration effects under fill mining condition", Blasting, 26(4), 2009, pp. 81-84.

16. Liu Y. P., Gong M., Zhao J. Q., and Huang G. H., "Study on blasting vibration control during mining near the fill-mass", Mining and Metallurgical Engineering, 31(5), 2011, pp. 13-17.

17. Shi D. Y., "The explicit dynamic analysis based on ANSYS/LSDYNA 8.1", Beijing: Tsinghua University Press, China, 2005, pp. 212.

18. Lee L. E., Homing H. C., and Kury J. W., "Lawrence Livermore laboratory report. UCRL-50442", Livermore: Lawrence Livermore laboratory, USA, 1986, pp. 22-29.

19. LSTC., "LS-DYNA user manual version non dynamic of structure in three dimension", California: Livermore Software Technology Corporation (LSTC), USA, 2003, 784-785.

20. Bai J. Z., "The Theory Foundation and Example Analysis of LSDYNA3D”, Beijing: Science Press, China, 2005, 74-103.

21. Jiang F. L., "The evaluation of ore-rock's blast stability in metal mine and the theoretical and experimental study of deep-hole blasting parameters' optimization in underground stope", Changsha: Doctoral dissertation of Central South University, China, 2011, pp. 7-8.

22. Wang Y. J., and Liang K. S., "Blasting Engineering”, Wuhan: Wuhan University of Technology Press, China, 2007, pp. 285-289.

23. Li X. B., "Drilling and Blasting Engineering", Changsha: Central South University Press, China, 2011, pp. 211-216.

24. Tang H., Li H. B., Zhou Q. C., Xia X., Liu B., and Li J. R., "Experimental study of vibration effect of presplit blasting", Chinese Journal of Rock Mechanics and Engineering, 29(11), 2010, pp. 2277-2284.

25. Dowding C. H., "Estimating earthquake damage from explosion testing of full-scale tunnels", Adv Tunnel Tech Subsurface Use, 4(3), 1984, pp. 113-117. 